\title{
Detecção do genótipo 4 do vírus da hepatite C em Salvador, BA
}

\author{
Detection of genotype 4 of the hepatitis C virus in Salvador, BA
}

\author{
Maria Alice Sant' Anna Zarife ${ }^{1,2}$, Eline Carvalho Pimentel de Oliveira ${ }^{1}$, \\ Jane Maria Santos Leal Romeu ${ }^{1}$ e Mitermayer Galvão dos Reis ${ }^{2}$
}

\begin{abstract}
RESUMO
É descrito o primeiro caso de detecção do genótipo 4 do vírus da hepatite C (VHC) em Salvador, BA. Foram utilizados os testes de RT-PCR para detecção do VHC-RNA, e o LIPA para genotipagem. O genótipo 4 responde mal ao tratamento, sendo portanto importante a busca ativa dos contactantes.
\end{abstract}

Palavras-chaves: Vírus da hepatite C. VHC-RNA. Genotipagem.

\begin{abstract}
The first detected case of genotype 4 of the hepatitis $C$ virus (HCV) in Salvador, Bahia, is described. RT-PCR tests were used to detect HCV-RNA, and LIPA was used for genotyping. Genotype 4 responds poorly to treatment, and it is therefore important to actively search for people who have been in contact with it.
\end{abstract}

Key-words: Hepatitis C virus. HCV-RNA. Genotyping.

A hepatite $C$ é um dos principais problemas de Saúde Pública no Brasil e no mundo, por ser uma causa importante de doença no fígado em adultos, com elevada taxa de cronificação, evolução para a cirrose e desenvolvimento de carcinoma hepatocelular ${ }^{4}$.

0 vírus da hepatite $\mathrm{C}$ (VHC) segundo dados da OMS, atinge entre 150 e 200 milhões de pessoas em todo o mundo. Tratase de uma epidemia silenciosa, em que a maioria dos pacientes evolui de forma assintomática por muitos anos, só obtendo diagnóstico de forma incidental.

No Brasil, em estudos realizados com doadores de sangue, a soroprevalência do VHC varia de 1 a $5 \%{ }^{10}$. Na Bahia, em Salvador, um estudo de base populacional demonstrou uma prevalência de $1,5 \%$ da infecção pelo $\mathrm{VHC}^{11}$.

A elevada taxa de mutação do VHC (1,44 a 1,92 x 10-3 substituições de nucleotídeos/local no genoma/ano) determina a sua classificação em grupos filogenéticos. Apesar de não haver um sistema de classificação padronizado para as variedades genéticas, a maioria dos investigadores concorda que existem pelo menos seis genótipos principais e uma série de subtipos ${ }^{7}$, que hoje já se constituem em mais de $50^{3}$.
Dados epidemiológicos sugerem que a distribuição dos genótipos do VHC varia entre diferentes regiões ${ }^{2}$. Os genótipos 1, 2, e 3 estão mais presentes no Japão, Europa Ocidental, América do Norte e América do Sul; o genótipo 4, na África Setentrional e Central e no Oriente Médio; o genótipo 5 na África do Sul e o 6 no Sudoeste Asiático ${ }^{6}$.

No Brasil, um estudo sobre a distribuição dos genótipos ${ }^{1}$ coletadas de pacientes cronicamente infectados pelo $\mathrm{VHC}$, em laboratórios de diferentes cidades do país, demonstrou que 64,9\% eram do genótipo 1, 4,6\% do genótipo 2, 30,2\% do genótipo 3, 0,2\% do genótipo 4, e 0,1\% do genótipo 5. Em todas as regiões, o genótipo 1 foi o mais freqüente, principalmente na região norte; o genótipo 2 foi mais prevalente na região centro-oeste, especialmente no Mato Grosso, enquanto que o genótipo 3 foi mais comum na região sul; os genótipos 4 e 5 foram raramente encontrados, e somente no estado de São Paulo, na região sudeste. Na Bahia, em amostras coletadas de pacientes atendidos no Serviço de Hepatologia do Hospital Prof. Edgard Santos, foi demonstrado também o predomínio do genótipo $1(62,7 \%)$, seguido pelos genótipos $3(21,7 \%)$ e $2(3,6 \%)^{8}$. Nenhum genótipo 4 foi encontrado.

\footnotetext{
1. Laboratório Central de Saúde Pública Professor Gonçalo Moniz Salvador, BA. 2. Laboratório de Patologia e Biologia Molecular do Centro de Pesquisas Gonçalo Moniz/Fundação Oswaldo Cruz, Salvador, BA.

Endereço para correspondência: Dra. Maria Alice Sant'Anna Zarife. LACEN-BA. R. Waldemar Falcão 123, Brotas, 40295-001 Salvador, BA.

Tel: 5571 3356-2299; fax: $55713356-0139$

e-mail: mzarife@cpqgm.fiocruz.br; azarife@hotmail.com

Recebido para publicação em 6/6/2005

Aceito em 5/12/2006
} 


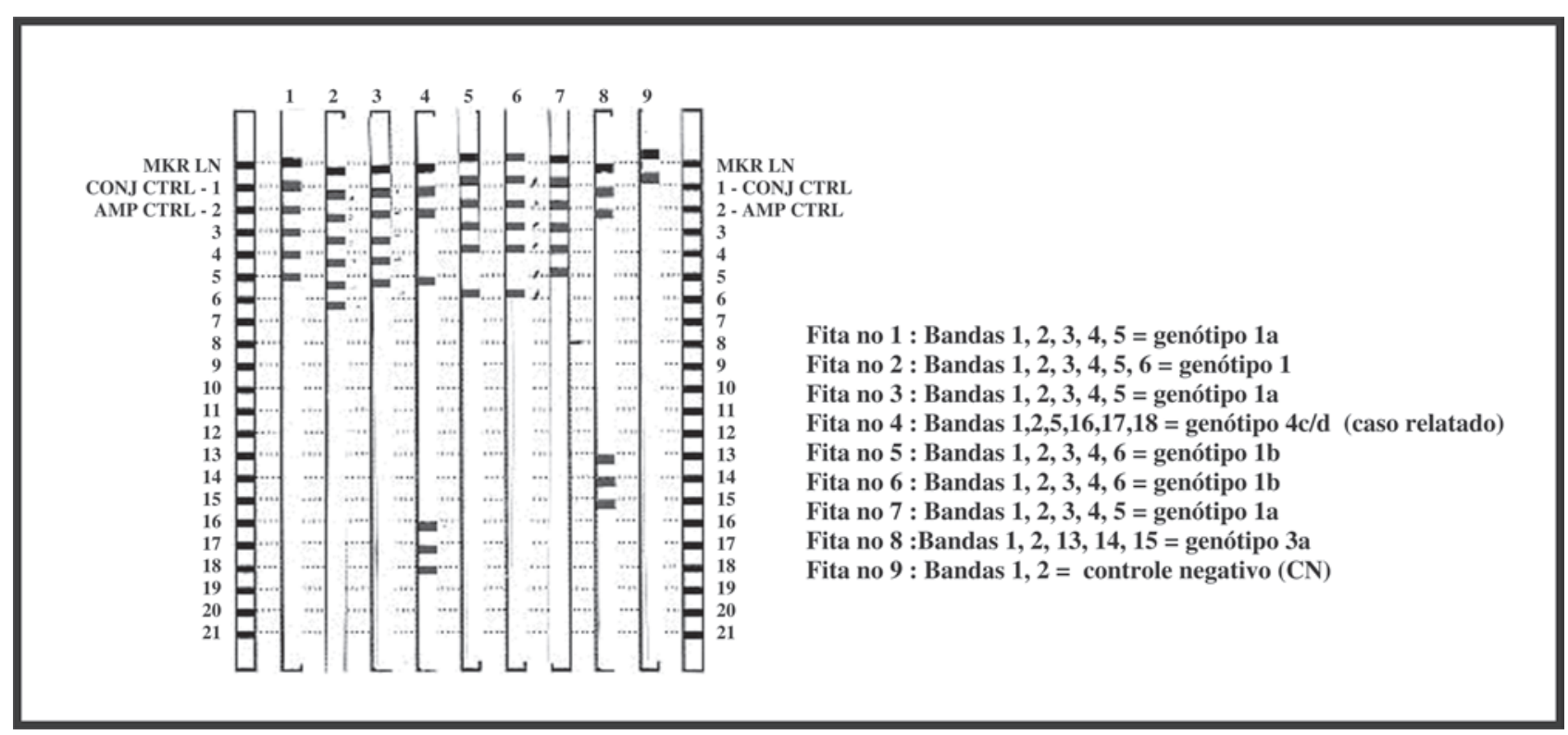

Figura 1 - Padrões de bandas verificadas em diferentes amostras de soro e suas interpretações, de acordo com o fabricante do teste LIPA.

0 objetivo deste trabalho foi descrever o primeiro caso de genótipo 4 em Salvador, Bahia, num paciente atendido no Laboratório Central de Saúde Pública (LACEN-BA), em março de 2005 .

\section{RELATO DE CASO}

Homem de 44 anos, natural de Salvador, solteiro, portador do HIV e HTLV, fazendo uso de anti-retrovirais para o HIV. Realizou a primeira detecção de anticorpos para o vírus $\mathrm{C}$ da hepatite (anti-VHC) em 2004, quando o resultado foi repetidamente positivo. Não possui resultados das aminotransferases (ALT e AST), nem de biópsia hepática.

0 paciente reportou ser homosexual, ter residido em Portugal no período de 1989 a 1999, quando visitou a Itália e a Espanha. Nessa época, fez uso de drogas intravenosas com compartilhamento de seringa, e inalou cocaína com canudinho. Apresenta uma tatuagem no antebraço esquerdo desde 1982. Não faz uso do álcool.

O paciente, originário do Hospital Central Roberto Santos, foi atendido no LACEN-BA com solicitação para detecção do RNA do vírus C (VHC-RNA) e genotipagem. Foram colhidos $5 \mathrm{ml}$ de sangue por punção venosa, a vácuo, em tubo estéril com EDTA. 0 tubo foi centrifugado, em até duas horas após a coleta, a 1300rpm durante 20 minutos, para obtenção do plasma. Foram feitas três alíquotas do plasma e armazenadas a $-70^{\circ} \mathrm{C}$. Todo esse procedimento foi repetido em uma segunda amostra de sangue, para confirmação dos resultados.

Para a detecção do VHC-RNA, foi realizada a RT-PCR (ROCHE, AMPLICOR), e para a genotipagem foi utilizado o LIPA (BAYER), segundo as normas do fabricante. 0 resultado da RT-PCR foi positivo, e na genotipagem, foram visualizadas as bandas 1, 2, 5, 16, 17 e 18, caracterizando o genótipo 4c/d (Figura 1).

\section{DISCUSSÃo}

Este é o primeiro relato da presença do genótipo 4 na Bahia. No Brasil este genótipo só foi encontrado, até o momento, em São Paulo ${ }^{1}$.

0 genótipo 4 predomina na África Setentrional e Central e no Oriente Médio ${ }^{6}$.

0 paciente do nosso estudo reportou ter residido em Portugal durante 10 anos, quando fez uso de drogas intravenosas, com compartilhamento de seringa, e de drogas inalatórias, com utilização do canudinho. 0 uso de drogas intravenosas é um importante fator de risco para a aquisição do VHC , assim como a utilização do canudinho, já que a principal via de transmissão do VHC é a parenteral. 0 mais provável, portanto, é que este paciente tenha se infectado neste período.

Por ser um genótipo que, como o genótipo 1, responde mal ao tratamento ${ }^{12}$, faz-se necessária a busca ativa de outros casos a partir deste caso index, e a implementação de uma vigilância para o esclarecimento daqueles casos que não foram previamente genotipados como 1, 2, ou 3.

\section{REFERÊNCIAS}

1. Campiotto S, Pinho JRR, Carrilho FJ, Silva LC, Souto FJD, Spinelli V, Pereira LMMB, Coelho HSM, Silva A0, Fonseca JC, Rosa H, Lacet CMC, Bernardini AP. Geographic distribution of hepatitis C vírus genotypes in Brazil. Brazilian Journal of Medical and Biological Research 38: 41-49, 2005.

2. Davidson F, Simmonds P, Ferguson JC, Jarvis LM, Dow BC, Follett EAC, Seed CRG, Krusius T, Lin C, Megyesi CA, Kiyokawa H, Olim G, Dusaisamy G, Cuypers T, Saeed AA, Teo D, Conradie J, Kew MC, Lin M, Muchaprayoon C, Ndimble OK, Yap PML. Survey of major genotypes and subtypes of hepatitis C virus using RFLP of sequences amplified from the 5' non-coding region. Journal of General Virology 76: 1197-1204, 1995.

3. Farci P, Purcell RH. Clinical significance of hepatitis C vírus genotypes and quasispécies. Semininars in Liver Diseases 20:103-126, 2000. 
4. Lauer GM, Walker BD. Hepatitis C virus infection. New England Journal of Medicine 345:41-52, 2001.

5. Majid A, Holmes R, Desselberg U, Simmonds P, McKee TA. Molecular epidemilogy of hepatitis $\mathrm{C}$ virus infection among intravenous drug users in rural communities. Journal of Medical Virology 46: 48-51, 1995.

6. Nousbaum J. Les sous-types génomics du virus de 1 hepatite C: épidemiologie, diagnostic et conséquences cliniques. Bulletin de la Societé de Pathologie Exottique 91:29-33, 1998.

7. Schreier E, Roggendorf M, Driesel G, Hoehne M, Viazov S. Genotypes of hepatitis $\mathrm{C}$ virus isolates from different parts of the world. Archives of Virology 11(suppl):185-193, 1996.

8. Silva LK, Paraná R, Souza SP, Berby F, Kay A, Trepó C, Santana N, Cotrim H, Lyra LG, Reis MG. Hepatitis $\mathrm{C}$ vírus genotypes in a northeastern area of Brazil. American Society of Tropical Medicine and Hygiene 62:257-260, 2000
9. Simmonds P, Holmes E, Cha T, Chan SW, McOmish F, Irvine B, Beall E, Yap PL, Kolberg J, Urdea MS. Classification of hepatitis C virus into six major genotypes and a series of subtypes by phylogenetic analysis of the NS5 region. Journal of General Virology 74:2391-2399, 1993.

10. Wasley A, Alter JM. Epidemiology of hepatitis C: geographic differences and temporal trends. Seminars in Liver Diseases 20: 1-16, 2000.

11. Zarife MAS, Silva LK, Silva MBS, Lopes GB, Barreto ML, Teixeira MG, Dourado I, Reis MG. Prevalence of hepatitis C virus infection in northeastern Brazil: a population-based study. Transactions of the Royal Society of Tropical Medicine and Hygiene 100: 663-668, 2006.

12. Zylberberg $\mathrm{H}$, Chaix ML, Bréchot $\mathrm{C}$. Infection with hepatitis $\mathrm{C}$ virus genotype 4 is associated with a poor response to interferon-alpha. Annals of Internal Medicine 132: 845-846, 2000. 